\title{
An analysis of clinical risk factors for adolescent scoliosis caused by spinal cord abnormalities in China: Proposal for a selective whole-spine MRI examination scheme
}

\section{Wei Xu}

Tongren Hospital Shanghai Jiaotong University School of Medicine

\section{Xiangyang Zhang}

Tongren Hospital Shanghai Jiaotong University School of Medicine

\section{Ying Zhu}

Tongren Hospital Shanghai Jiaotong University School of Medicine zhikun li ( $\square$ scoliosis_lizk@126.com )

Shanghai Jiao Tong University School of Medicine https://orcid.org/0000-0001-6829-0030

\section{Xiaodong Zhu}

Tongren Hospital Shanghai Jiaotong University School of Medicine

\section{Dachuan Li}

PLA Naval Medical University

\section{Jianjun Jia}

PLA Naval Medical University

\section{Liwei Chen}

Tongren Hospital Shanghai Jiaotong University School of Medicine

\section{Silian Wang}

Tongren Hospital Shanghai Jiaotong University School of Medicine

\section{Yushu Bai}

Changhai Hospital

\section{Ming Li}

Changhai Hospital

\section{Research article}

Keywords: Adolescent scoliosis; MRI; Neural axis abnormalities; Prevalence

Posted Date: November 14th, 2019

DOI: https://doi.org/10.21203/rs.2.17338/v1 
License: (c) (i) This work is licensed under a Creative Commons Attribution 4.0 International License. Read Full License 


\section{Abstract}

Background This study examined the risk factors for non-idiopathic scoliosis with intramedullary abnormalities, explored the feasibility of whole-spine MRI, and provided a theoretical basis for the routine diagnosis and treatment of adolescent idiopathic scoliosis. Method The clinical data of adolescent scoliosis patients who were admitted to Shanghai Tongren Hospital and Shanghai Changhai Hospital between July 1, 2013, and December 31, 2018, were reviewed. According to the whole-spine MRI results, the patients were divided into either the idiopathic group or the intramedullary abnormality group. Sex, age, main curvature angle, main curvature direction, kyphosis angle, scoliosis type, coronal plane balance, sagittal plane balance, abdominal wall reflex, sensory abnormality, ankle clonus and tendon reflexes were compared between the two groups. Student's t test was used to evaluate the differences in the continuous variables, and the chi-square test was used to evaluate the differences in the categorical variables. Fisher's exact test was applied to detect the difference in the rate of intraspinal anomalies between the groups. Logistic regression was used to evaluate the correlation between the multivariate risk factors and intramedullary abnormalities. Result $A$ total of 714 adolescent scoliosis patients with a mean age of 13.5 (10-18 years) were included in the study, and intramedullary abnormalities were found in $68(9.5 \%)$ patients. There were statistically significant differences in the incidence rates of intramedullary abnormalities between males and females, left and right thoracic curvatures, angular scoliosis and smooth scoliosis, and abnormal abdominal wall reflex and ankle clonus $(P<0.01)$. Logistic regression showed that the ratios for sex, scoliosis direction, scoliosis type, abdominal wall reflex and ankle clonus were $2.987,3.493,4.823,3.94$ and 8.083 , respectively. The ROC curve showed a sensitivity of $66.18 \%$ and a specificity of $89.01 \%$, and the Youden index corresponding to the optimal critical point was 0.5519 . Conclusion Risk factors associated with adolescent scoliosis caused by abnormal intramedullary abnormalities included male sex, thoracic scoliosis on the left side, sharp curvature of the spine, abnormal abdominal wall reflex and ankle clonus. These clinical indicators suggest that there is a high-risk adolescent scoliosis population who should undergo whole-spinal MRI preoperatively to rule out intramedullary abnormalities.

\section{Background}

Scoliosis is a common three-dimensional spinal deformity that can be clearly diagnosed with a physical examination. Scoliosis can be classified as idiopathic, congenital, or neuromuscular scoliosis; neurofibromatosis scoliosis; spinal scoliosis caused by intramedullary abnormalities; etc. Idiopathic scoliosis is the most common form, accounting for approximately $75-85 \%$ of all scoliosis cases ${ }^{1,2}$. Magnetic resonance imaging (MRI) is the gold standard for identifying idiopathic scoliosis, but the cause of scoliosis often remains unidentified due to the associated high costs and poor medical environments, e.g., long wait times and a lack of MRI equipment ${ }^{3}$.

Intramedullary abnormalities can lead to scoliosis deformities, including Chiari malformations, syringomyelias, and hydromyelias ${ }^{4}$. Idiopathic scoliosis is difficult to diagnose based on a patient's appearance. The gold standard MRI examination is not a routine scoliosis examination; therefore, 
patients with scoliosis caused by spinal cord abnormalities are easily misdiagnosed with idiopathic scoliosis, but there are differences in the axzz primarily supportive, and surgical correction may be required if the scoliosis continues to progress. Spinal scoliosis with intramedullary abnormalities should first be treated with neurosurgery to resolve the cause of scoliosis. Patients who are misdiagnosed and treated for idiopathic scoliosis who undergo direct scoliosis correction may suffer permanent nerve damage, leading to serious complications, such as lower limb weakness, pain and numbness, and even paralysis ${ }^{6}$. On the other hand, the early detection of scoliosis caused by intramedullary abnormalities and timely neurosurgical treatment can prevent further exacerbation; therefore, some scholars believe that MRI should be a routine examination for patients with scoliosis. However, other scholars believe that because the incidence of scoliosis caused by intramedullary lesions is low, MRI screening is a waste of money, time and medical resources; therefore, the diagnosis of scoliosis does not require an MRI examination, and an MRI examination can cause panic among patients, which is still the focus of debate ${ }^{7}$.

In recent years, several articles have suggested that MRI examination of scoliosis patients is necessary. Studies have found that the incidence of scoliosis with spinal cord abnormalities is $6.3 \%$ to $9.9 \% 3,4$. However, considering the current medical situation in China, it is particularly difficult for all patients with scoliosis to undergo an MRI examination of the whole spine. Therefore, this study aims to explore the risk factors for scoliosis caused by intramedullary abnormalities, identify the patient population that would benefit from selective MRI examination, explore the feasibility of MRI examination and provide a theoretical basis for the routine diagnosis and treatment of scoliosis.

\section{Method}

The ethics committee approved the review of adolescent scoliosis surgery cases in Shanghai Tongren Hospital and Shanghai Changhai Hospital before December 2018 for this retrospective study.

\section{Research Objective}

(1) Inclusion criteria: patients with scoliosis aged 10-18 years with complete spinal X-ray and MRI data.

(2) Exclusion criteria: patients with congenital scoliosis (bone dysplasia), neuromuscular scoliosis, neurofibromatosis scoliosis, metabolic scoliosis, Marfan syndrome and other clearly diagnosed scoliosis types.

(3) Groupings: the spinal cord abnormality group (Group A) contained patients who exhibited lesions in the spinal cord, such as Chiari malformations, syringomyelia, and hydromyelia, on MRI examination. The idiopathic group (Group B) contained patients with no abnormalities on MRI examination.

\section{Data Measurement and Recording}

(1) General information: age and sex. 
(2) Imaging examination: angle of the main bend, scoliosis direction (thoracic scoliosis on the left, thoracic scoliosis on the right), angle of thoracic vertebrae kyphosis, and scoliosis shape (Figure 1, smooth shape is the concave side line is a smooth curve, angular shape is the concave side line is a angular curve).

(3) Neurologic examination: assessment of motor, sensory, and reflex functions of the upper and lower extremities; pathologic signs; abdominal reflexes; tendon reflexes (radial membrane reflex, knee reflex, Achilles tendon reflex); paraesthesia; and ankle clonus.

\section{Clinical and Imaging Evaluation}

A whole-spine 1.5 T Philips MRI machine (Philips, the Netherlands) was used to detect potential spinal abnormalities, including Chiari malformations, syringomyelia, vertebral compression, longitudinal spinal fractures, and spinal cord tumours. All diagnoses were made by a spine surgeon and reviewed by an experienced radiologist. According to the MRI findings, patients were assigned the spinal cord abnormality group or the idiopathic group to determine the imaging and clinical indicators of spinal cord abnormalities in the two groups.

Positive and lateral X-ray images of the whole spine were taken to measure the Cobb angle, scoliosis direction, scoliosis shape, thoracic kyphosis angle from T5 to T12 in the sagittal plane (defined as kyphosis deformity if the angle was greater than 10 degrees), the coronal plane balance (according to the central sacral vertical line (CSVL)), and the sagittal plane balance (according to the C7-S1 line) in the main bend.

\section{Statistical Analysis}

Sex, age, main curvature angle, kyphosis angle, scoliosis direction, scoliosis type, coronal plane balance, sagittal plane balance, abdominal wall reflex, sensory abnormalities, ankle clonus and tendon reflexes were compared between the spinal cord abnormality group and the idiopathic group. Statistical analyses were performed using the SPSS 21.0 statistical package (SPSS Inc., Chicago, IL). Continuous variables were compared using t tests, and rates were compared using chi-square tests. Fisher's exact test was used to compare the rates of internal abnormalities between the groups. Logistic regression was used to evaluate the correlation between multiple variables and the incidence of intramedullary abnormalities, with the following values: intramedullary abnormalities $=1$ and no abnormalities $=0$. A $p$ value less than 0.05 was defined as statistically significant.

\section{Results}

Patient data from July 2013-December 2018 were retrieved from Tongren Hospital in Shanghai and from Shanghai Changhai Hospital. A total of 714 adolescent patients with scoliosis met the inclusion criteria. The patients had an average age of 13.5 (10 to 18) years, and 68 (9.5\%) patients presented intramedullary abnormalities. Thirty-one patients underwent neurosurgical procedures, such as cerebellar 
tonsillar hernia resection, expanded foramen magnum decompression, vertebral reconstruction, and spinal cord cavity catheter drainage. The patients' characteristics are shown in Table 1.

There were significant differences in the incidence rates of intramedullary abnormalities between males and females, patients with left and right thoracic curvatures, patients with angular scoliosis and smooth scoliosis, and patients with abdominal wall reflex abnormalities and ankle clonus. There were no significant differences between the other influencing factors, as shown in Table 2.

Logistic regression showed that patients with intramedullary abnormalities were 2.987 times more likely to be male, were 3.493 times more likely to present scoliosis on the left thoracic side, were 4.823 times more likely to have lateral smooth scoliosis, were 3.94 times more likely to have abnormal abdominal wall reflexes, and were 8.083 times more likely to have ankle clonus than patients with idiopathic scoliosis, as shown in Table 3.

Regression equation:

Logit $(P)=-3.522+1.094$ sex +1.251 scoliosis direction +1.573 scoliosis shape +1.371 abdominal wall reflex +2.090 ankle clonus

The area under the receiver operating characteristic (Receiver Operating Characteristic,ROC) curve for the incidence of intramedullary abnormalities was 0.842 (95\% confidence interval: $0.813-0.868, \mathrm{P}<0.001)$. The sensitivity was $66.18 \%$, the specificity was $89.01 \%$, and the Youden index corresponding to the optimal critical point was 0.5519 , as shown in Figure 2. The ROC reflects the relationship between the sensitivity and specificity of the prediction formula. Generally speaking, an AUC(Area Under Curve) between 0.7 and 0.9 indicates high accuracy of the prediction formula. Figure 3 shows a 13-year-old female who weighed $38 \mathrm{~kg}$, was $138 \mathrm{~cm}$ tall and had a spinal deformity for 1 year.

Coronal Plane: T1-T6: 35, T7-L3:100 $\mathrm{CB}: 22$ mm, Risser: 0 1

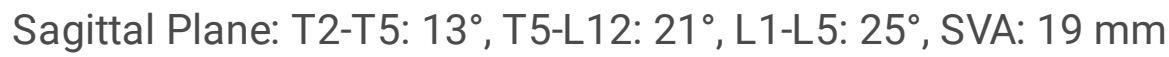

The patient presented left thoracic curvature, right lumbar curvature, an abnormal abdominal wall reflex, paraesthesia, and ankle clonus.

The whole-spine MRI showed a Chiari malformation and syringomyelia.

First step: In the first step of the patient's treatment, Neurosurgery department performed posterior fossa decompression.Second step: In the second step,Spinal surgery was performed to correct scoliosis from T4 to L4.Spinal surgery was performed 3-6 months after neurosurgery.

\section{Discussion}

According to the appointment registration statistics of major hospitals in Shanghai, the wait time for a spinal MRI appointment is approximately 4 weeks, and the cost of an MRI examination for a single spinal 
section (cervical spine, thoracic spine, and lumbar spine) is $460 \mathrm{RMB}$. A whole-spine MRI examination costs 1380 RMB; however, $90 \%$ of the cost will be reimbursed by Shanghai Medical Insurance, and only $10 \%$ will be paid by the patients themselves. According to previous studies and this study, the incidence of intramedullary abnormalities in patients initially diagnosed with idiopathic scoliosis is approximately $6.3 \%$ to $9.9 \%{ }^{4}$. As $90.1 \%$ to $93.7 \%$ of patients have idiopathic scoliosis, a whole-spine MRI to determine whether there is an intramedullary abnormality could be considered a waste of resources. Therefore, some scholars believe that whole-spine MRI is not necessary for idiopathic scoliosis patients ${ }^{8}$. However, there have been cases of spinal cord injury in patients with idiopathic scoliosis who underwent surgical correction, with very serious consequences ${ }^{9}$. The purpose of this study was to develop accurate intramedullary abnormality screening criteria to reduce medical resource waste. A retrospective study with a large sample size found that intramedullary abnormalities were associated with five risk factors. The results showed that if the incidence of the five factors associated with intramedullary abnormality was $66.18 \%$, an MRI should not be conducted, but if the incidence rate of the five factors was $89.01 \%$, the patient should undergo a whole-spine MRI. Therefore, regarding selective whole-spine MRI, applying the five risk factors as a condition for whole-spine MRI can improve the whole-spine MRI intramedullary abnormality positivity rate and reduce unnecessary medical treatments. This scheme is completely feasible in the current Chinese medical environment. The more consistent the risk factors are, the higher the probability of intramedullary abnormalities will be. Selective examinations can be conducted for highrisk patients to further clarify the aetiology of adolescent scoliosis, which provides a theoretical basis for selective MRI examination and has important clinical practical significance.

Nearly 10 years of research was obtained from PubMed (Table 4); thus, this study includes the second largest research sample to date. The risk factors identified in this study can be divided into three categories, namely, general, imaging, and neurologic characteristics; a total of 12 clinical indicators were included in the correlation analysis. The content of this study is more comprehensive than that in previous studies and is shown in Table $4^{3,6-8,10-25}$.

This study retrospectively analysed the incidence of intramedullary abnormalities in adolescent scoliosis patients and proposed the idea of selective whole-spine MRI examination, which has a strong guiding role in clinical work. However, this study had the following limitations. 1. Patients from two hospitals were included in the analysis, and this study contains the second largest sample size (714 patients) in the current literature. However, the sample size is still insufficient to study disease incidence, although this did not affect the research conclusion. 2. Although 12 factors were included in this study, the specificity (66.18\%) and sensitivity (89.01\%) for predicting intramedullary abnormalities still require further improvement; the factors affecting intramedullary abnormalities included in this study are not sufficiently comprehensive. 3. Due to the limitations of retrospective studies, the data must be supplemented with additional prospective studies that include further analyses of influencing factors and larger sample sizes to obtain more-conclusive research results.

In this study, the incidence of adolescent scoliosis caused by an intramedullary abnormality was $9.5 \%$. MRI assessment showed that the spinal cords of patients were not excessively damaged. We recommend 
that high-risk patients (males and those with a lateral thoracic spine angle on the left side of the curve, an angular curve, abdominal wall reflection and ankle clonus) undergo selective spinal MRI, because neurological complications (paraplegia, nerve damage, etc.) can cause irreparable damage. These complications can be prevented by preoperative management. For example, syringomyelia causes scoliosis, and scoliosis correction before appropriate neurosurgery or surgical interventions can avoid spinal cord damage during scoliosis correction surgery. Therefore, the spine surgeon should pay close attention to the diagnosis of preoperative patients. Currently, we are using this method to conduct a prospective study on high-risk adolescent patients with scoliosis to further verify the feasibility of this method and further identify risk factors while increasing the sample size to further improve the prediction equation.

\section{Conclusion}

Adolescent scoliosis caused by intramedullary abnormalities is associated with male sex, thoracic scoliosis on the left side, a sharp curve, abdominal wall reflection and ankle clonus. The incidence of adolescent scoliosis caused by intramedullary abnormalities was approximately $9.5 \%$. Clinical indicators suggest that there is a high-risk population of adolescent patients with scoliosis who should undergo whole-spine MRI preoperatively to rule out intramedullary abnormalities.

\section{Abbreviations}

Magnetic Resonance Imaging,MRI

Central Sacral Vertical line,CSVL

Receiver Operating Characteristic,ROC

Area Under Curve,AUC

\section{Declarations}

Ethics approval and consent to participate.

If the participant is a child (under 16) from a parent or guardian, the informed consent to participate has been obtained.

This retrospective study was approved and consented to participate by the Ethics Committee

Consent for publication

Not applicable. 
Competing interests

The authors declare that they have no competing financial interests to disclose and no financial conflicts of interest exist for any of the authors.

Funding

1.The Sixth people's hospital of Shanghai medical group projects(ly201802)Mr. ZHIKUN LI

2.Sponsored by Shanghai Sailing Program (19YF1444500)Mr. ZHIKUN LI

3.Changning district committee of science and technology(CNKW2017Y07)Mr. ZHIKUN LI

4.Project supported by Shanghai Tongren Hospital(TRYJ201605)Mr. ZHIKUN LI

5.Changning district health and family planning commission(20164Y003)Mr. ZHIKUN LI

Li zhikun is the main researcher of this study

Authors' contributions

$X W, Z X Y$ and ZY conceived and designed the study. CLW,LDC and JJJ measured and recorded the data. LZK and ZXD wrote the paper. WSL, BYS and LM reviewed and edited the manuscript. All authors read and approved the manuscript.

Acknowledgements

Wei Xu ,Zhang Xiangyang and Zhu Ying are co-first authors,Li Zhikun and Zhu Xiaodong are cocorresponding author.

Availability of data and materials

not applicable

\section{References}


1. Newton Ede MM, Jones SW. Adolescent idiopathic scoliosis: evidence for intrinsic factors driving aetiology and progression. International orthopaedics. Oct 2016;40(10):2075-2080.

2. Hoashi JS, Cahill PJ, Bennett JT, Samdani AF. Adolescent scoliosis classification and treatment. Neurosurgery clinics of North America. Apr 2013;24(2):173-183.

3. Pereira EAC, Oxenham M, Lam KS. Intraspinal anomalies in early-onset idiopathic scoliosis. The bone \& joint journal. Jun 2017;99-B(6):829-833.

4. Heemskerk JL, Kruyt MC, Colo D, Castelein RM, Kempen DHR. Prevalence and risk factors for neural axis anomalies in idiopathic scoliosis: a systematic review. The spine journal : official journal of the North American Spine Society. Jul 2018;18(7):1261-1271.

5. Zhao Q, Shi B, Sun X, et al. Do untreated intraspinal anomalies in congenital scoliosis impact the safety and efficacy of spinal correction surgery? A retrospective case-control study. Journal of neurosurgery. Spine. Apr 5 2019:1-6.

6. Martin BD, McClung A, Denning JR, Laine JC, Johnston CE. Intrathecal Anomalies in Presumed Infantile Idiopathic Scoliosis: When Is MRI Necessary? Spine deformity. Nov 2014;2(6):444-447.

7. Diab M, Landman Z, Lubicky J, et al. Use and outcome of MRI in the surgical treatment of adolescent idiopathic scoliosis. Spine. Apr 15 2011;36(8):667-671.

8. Zhang W, Sha S, Xu L, Liu Z, Qiu Y, Zhu Z. The prevalence of intraspinal anomalies in infantile and juvenile patients with "presumed idiopathic" scoliosis: a MRI-based analysis of 504 patients. BMC musculoskeletal disorders. Apr 27 2016;17:189.

9. Ng SY, Bettany-Saltikov J. Imaging in the Diagnosis and Monitoring of Children with Idiopathic Scoliosis. The open orthopaedics journal. 2017;11:1500-1520.

10. Faizah MZ, Ng KL, Te BC, et al. Association of Cobb angle progression and neuraxial abnormality on MRI in asymptomatic Adolescent Idiopathic Scoliosis. The Medical journal of Malaysia. Jun 2016;71(3):122-125.

11. Ameri E, Andalib A, Tari HV, Ghandhari H. The Role of Routine Preoperative Magnetic Resonance Imaging in Idiopathic Scoliosis: A Ten Years Review. Asian spine journal. Aug 2015;9(4):511-516.

12. Karami M, Sagheb S, Mazda K. Evaluation of coronal shift as an indicator of neuroaxial abnormalities in adolescent idiopathic scoliosis: a prospective study. Scoliosis. 2014;9:9.

13. Koc T, Lam KS, Webb JK. Are intraspinal anomalies in early onset idiopathic scoliosis as common as once thought? A two centre United Kingdom study. European spine journal : official publication of the European Spine Society, the European Spinal Deformity Society, and the European Section of the Cervical Spine Research Society. Jun 2013;22(6):1250-1254.

14. Qiao J, Zhu Z, Zhu F, et al. Indication for preoperative MRI of neural axis abnormalities in patients with presumed thoracolumbar/lumbar idiopathic scoliosis. European spine journal : official publication of the European Spine Society, the European Spinal Deformity Society, and the European Section of the Cervical Spine Research Society. Feb 2013;22(2):360-366.

15. Singhal R, Perry DC, Prasad S, Davidson NT, Bruce CE. The use of routine preoperative magnetic resonance imaging in identifying intraspinal anomalies in patients with idiopathic scoliosis: a 10- 
year review. European spine journal : official publication of the European Spine Society, the European Spinal Deformity Society, and the European Section of the Cervical Spine Research Society. Feb 2013;22(2):355-359.

16. Lee RS, Reed DW, Saifuddin A. The correlation between coronal balance and neuroaxial abnormalities detected on MRI in adolescent idiopathic scoliosis. European spine journal : official publication of the European Spine Society, the European Spinal Deformity Society, and the European Section of the Cervical Spine Research Society. Jun 2012;21(6):1106-1110.

17. Minkara A, Bainton N, Tanaka M, et al. High Risk of Mismatch Between Sanders and Risser Staging in Adolescent Idiopathic Scoliosis: Are We Guiding Treatment Using the Wrong Classification? Journal of pediatric orthopedics. Jan 222018.

18. Lee CS, Hwang CJ, Kim NH, et al. Preoperative Magnetic Resonance Imaging Evaluation in Patients with Adolescent Idiopathic Scoliosis. Asian spine journal. Feb 2017;11(1):37-43.

19. Nakahara D, Yonezawa I, Kobanawa K, et al. Magnetic resonance imaging evaluation of patients with idiopathic scoliosis: a prospective study of four hundred seventy-two outpatients. Spine. Apr 1 2011;36(7):E482-485.

20. Smucny M, Lubicky JP, Sanders JO, Carreon LY, Diab M. Patient self-assessment of appearance is improved more by all pedicle screw than by hybrid constructs in surgical treatment of adolescent idiopathic scoliosis. Spine. Feb 1 2011;36(3):248-254.

21. Landman Z, Oswald T, Sanders J, Diab M, Spinal Deformity Study G. Prevalence and predictors of pain in surgical treatment of adolescent idiopathic scoliosis. Spine. May 1 2011;36(10):825-829.

22. Richards BS, Sucato DJ, Johnston CE, et al. Right thoracic curves in presumed adolescent idiopathic scoliosis: which clinical and radiographic findings correlate with a preoperative abnormal magnetic resonance image? Spine. Sep 15 2010;35(20):1855-1860.

23. Wu L, Qiu Y, Wang B, Zhu ZZ, Ma WW. The left thoracic curve pattern: a strong predictor for neural axis abnormalities in patients with "idiopathic" scoliosis. Spine. Jan 15 2010;35(2):182-185.

24. Rajasekaran S, Kamath V, Kiran R, Shetty AP. Intraspinal anomalies in scoliosis: An MRI analysis of 177 consecutive scoliosis patients. Indian journal of orthopaedics. Jan 2010;44(1):57-63.

25. Pahys JM, Samdani AF, Betz RR. Intraspinal anomalies in infantile idiopathic scoliosis: prevalence and role of magnetic resonance imaging. Spine. May 20 2009;34(12):E434-438.

\section{Tables}

\section{Table.1 Overview of spinal anomalies}




\begin{tabular}{|l|l|}
\hline Anomalies & Number of cases (\%) \\
\hline Isolated Arnold-Chiari malformation & $49.5 \%$ \\
\hline Arnold-Chiari malformation combined with syringomyelia & $20.1 \%$ \\
\hline Isolated syringomyelia & $10 \%$ \\
\hline Tethered cord combined with diastematomyelia & $6 \%$ \\
\hline Diastematomyelia & $6 \%$ \\
\hline Tethered cord & $4 \%$ \\
\hline Intrinsic spinal cord tumor & $3 \%$ \\
\hline Syringomyelia combined with tethered cord and tumor & $1 \%$ \\
\hline Total number & 68 \\
\hline
\end{tabular}

\section{Table.2 Comparison between patients with and without neural abnormality on MRI screening examination}

\begin{tabular}{|c|c|c|c|}
\hline & $\begin{array}{l}\text { Intramedullary Abnormalities } \\
\qquad \mathrm{n}=68\end{array}$ & $\begin{array}{c}\text { Idiopathic } \\
\mathrm{n}=646 \\
\end{array}$ & $\mathrm{P}$ \\
\hline \multicolumn{4}{|l|}{ Gender } \\
\hline Maleø1口 & 38 & 148 & \multirow[t]{2}{*}{$<0.01^{b}$} \\
\hline Female $\square 0 \square$ & 30 & 498 & \\
\hline Age & $14.1 \pm 1.9$ & $14.3 \pm 1.7$ & $\mathrm{NS}^{\mathrm{a}}$ \\
\hline \multicolumn{4}{|l|}{ Imaging } \\
\hline Main Cobb & $39.6 \pm 8.1^{\circ}$ & $36.1 \pm 11.7^{\circ}$ & $\mathrm{NS}^{\mathrm{a}}$ \\
\hline Left Thoracic curveø1ロ & 15 & 74 & \multirow[t]{2}{*}{$0.012^{\mathrm{b}}$} \\
\hline Right Thoracic curve $\square 0 \square$ & 53 & 572 & \\
\hline T-Kyphosis $\square 1 \square$ & 17 & 50 & \multirow[t]{2}{*}{$<0.01^{b}$} \\
\hline No T-Kyphosis $\square 0 \square$ & 51 & 596 & \\
\hline Angular curve $1 \square$ & 16 & 61 & \multirow[t]{2}{*}{$<0.01^{\mathrm{b}}$} \\
\hline Smooth curve 00 & 52 & 585 & \\
\hline \multicolumn{4}{|l|}{ The trunk balance } \\
\hline Coronal-imbalance 1 1] & 5 & 42 & \multirow[t]{2}{*}{$\mathrm{NS}^{\mathrm{b}}$} \\
\hline Coronal-balance $₫ 0 \square$ & 63 & 604 & \\
\hline Sagittal-imbalance $1 \square$ & 9 & 70 & \multirow[t]{2}{*}{$\mathrm{NS}^{\mathrm{b}}$} \\
\hline Sagittal-balance $₫ 0 \square$ & 59 & 576 & \\
\hline \multicolumn{4}{|l|}{ Nervous System } \\
\hline Abnormal abdominal wall reflex $1 \square$ & 19 & 40 & \multirow[t]{2}{*}{$<0.01^{\mathrm{b}}$} \\
\hline No-Abnormal abdominal wall reflex $\square 0 \square$ & 49 & 606 & \\
\hline paresthesia!1 & 10 & 52 & \multirow[t]{2}{*}{$0.064^{\mathrm{b}}$} \\
\hline euesthesia 00 & 58 & 594 & \\
\hline Ankle clonus $\square 1 \square$ & 15 & 49 & \multirow[t]{2}{*}{$<0.01^{\mathrm{b}}$} \\
\hline No-Ankle clonus₫0ロ & 53 & 597 & \\
\hline Abnormal tendon reflex $\square 1 \square$ & 16 & 65 & \multirow[t]{2}{*}{$0.001^{\mathrm{b}}$} \\
\hline Normal tendon reflex凸0ם & 52 & 581 & \\
\hline
\end{tabular}

\section{a The student $t$ test}

b the chi-square test 
Table 3.Logistic regression results

\begin{tabular}{|c|c|c|c|c|}
\hline & $\mathrm{B}$ & $\mathrm{P}$ & OR & $95 \% \mathrm{CI}$ \\
\hline $\begin{array}{l}\text { Gender } \\
\text { Female } \\
\text { Male } \\
\end{array}$ & 1.094 & $<0.01$ & $\begin{array}{c}1 \\
2.987\end{array}$ & $1.612-5.534$ \\
\hline $\begin{array}{l}\text { Direction of Scoliosis } \\
\text { R-Thoracic curve } \\
\text { L-Thoracic curve }\end{array}$ & 1.251 & $<0.01$ & $\begin{array}{c}1 \\
3.493\end{array}$ & $1.756-6.948$ \\
\hline $\begin{array}{l}\text { T11-L2 Cobb } \\
\text { Normal } \\
\text { Kyphosis }\end{array}$ & -0.974 & 0.054 & $\begin{array}{c}1 \\
0.377\end{array}$ & $0.140-1.016$ \\
\hline $\begin{array}{l}\text { Shape of Curve } \\
\text { Smooth curve } \\
\text { Angular curve }\end{array}$ & 1.573 & $<0.01$ & $\begin{array}{c}1 \\
4.823\end{array}$ & $2.278-10.211$ \\
\hline $\begin{array}{l}\text { Coronal Plane } \\
\text { Imbalance } \\
\text { Balance } \\
\end{array}$ & -0.858 & 0.112 & $\begin{array}{c}1 \\
0.424\end{array}$ & $0.147-1.223$ \\
\hline $\begin{array}{l}\text { Sagittal Plane } \\
\text { Imbalance } \\
\text { Balance } \\
\end{array}$ & -0.226 & 0.637 & $\begin{array}{c}1 \\
0.798\end{array}$ & $0.312-2.041$ \\
\hline $\begin{array}{l}\text { Abdominal reflexes } \\
\text { Normal } \\
\text { Abnormal }\end{array}$ & 1.371 & $<0.01$ & $\begin{array}{c}1 \\
3.940\end{array}$ & $1.810-8.574$ \\
\hline $\begin{array}{l}\text { Feeling } \\
\text { Normal } \\
\text { Abnormal } \\
\end{array}$ & -0.119 & 0.817 & $\begin{array}{c}1 \\
0.888\end{array}$ & $0.324-2.433$ \\
\hline $\begin{array}{l}\text { Ankle Clonus } \\
\text { Normal } \\
\text { Abnormal } \\
\end{array}$ & 2.090 & $<0.01$ & $\begin{array}{c}1 \\
8.083\end{array}$ & $3.945-16.562$ \\
\hline $\begin{array}{l}\text { Tendon Reflex } \\
\text { Normal } \\
\text { Abnormal } \\
\end{array}$ & -0.828 & 0.088 & $\begin{array}{c}1 \\
0.437\end{array}$ & $0.168-1.132$ \\
\hline Constant & -3.522 & $<0.01$ & 0.030 & \\
\hline
\end{tabular}


Table 4. Recent 10 years of research on abnormal scoliosis in the spinal cord on Pubmed 


\begin{tabular}{|c|c|c|c|c|c|}
\hline Reference & Year & Author & Cases & Incidence Rate & Risk Factors \\
\hline & 2018 & Li Zhikun & 714 & $68(9.5 \%)$ & $\begin{array}{c}\text { male, thoracic scoliosis on the left, Sharp curve, } \\
\text { abdominal wall reflection anomaly and ankle } \\
\text { clonus anomaly }\end{array}$ \\
\hline 3 & 2017 & $\begin{array}{l}\text { Pereira } \\
\text { EAC }\end{array}$ & 71 & $4(5.6 \%)$ & - \\
\hline 9 & 2017 & $\begin{array}{l}\text { Choon Sung } \\
\text { Lee }\end{array}$ & 378 & $24(6.3 \%)$ & $\begin{array}{l}\text { Males and patients with increased thoracic } \\
\text { kyphosis }\end{array}$ \\
\hline 10 & 2016 & Wen Zhang & 504 & $94(19 \%)$ & $\begin{array}{c}\text { aged less than } 10 \text { years, being male } \\
\text { or having left thoracic or right lumbar curve. }\end{array}$ \\
\hline 11 & 2016 & Faizah & 19 & $5 \square 26 \%$ & $\begin{array}{l}\text { Cobb angle progression is not a reliable indicator } \\
\text { for predicting neuroaxial abnormality in patients } \\
\text { with asymptomatic AIS. }\end{array}$ \\
\hline 12 & 2015 & Ameri & 271 & $27(10 \%)$ & $\begin{array}{c}\text { The incidence of neuroaxial abnormalities was } \\
\text { higher in male patients and in those with early } \\
\text { onset disease. }\end{array}$ \\
\hline 13 & 2014 & Karami & 143 & $17(12 \%)$ & $\begin{array}{l}\text { A total spine MRI is recommended at presentation } \\
\text { in patients with younger age, abnormal neurologic } \\
\text { findings and severe coronal shift. }\end{array}$ \\
\hline 6 & 2014 & Martin & 43 & $7(16 \%)$ & $\begin{array}{c}\text { For younger patients with small curves }(<30 \\
\text { degrees ) who do not require orthopedic } \\
\text { treatment, MRI under sedation can be delayed or } \\
\text { avoided. }\end{array}$ \\
\hline 14 & 2013 & Koç & 72 & $8(11 \%)$ & - \\
\hline 15 & 2013 & Qiao & 446 & $35(8 \%)$ & $\begin{array}{c}\text { right curves, long curve span, apex } \\
\text { at thoracolumbar spine and hyperthoracic } \\
\text { kyphosis. }\end{array}$ \\
\hline 16 & 2013 & Singhal & 206 & $20(10 \%)$ & $\begin{array}{l}\text { There was no statistically significant difference } \\
\text { between the group of patients who had intrinsic } \\
\text { spinal cord anomalies on preoperative MRI and } \\
\text { those did not have a cord abnormality with } \\
\text { regard to age at presentation, gender, side of } \\
\text { dominant curve and degree of curve }\end{array}$ \\
\hline 17 & 2012 & Lee & 171 & $15(9 \%)$ & $\begin{array}{l}\text { Our audit demonstrates that neither coronal nor } \\
\text { sagittal misbalance should be used as an } \\
\text { indicator of neural axis abnormalities. }\end{array}$ \\
\hline 18 & 2011 & Nakahara & 472 & $18(4 \%)$ & $\begin{array}{l}\text { We recommend routine use of MRI in } \\
\text { male patients, younger than } 11 \text { years old, and } \\
\text { abnormal superficial abdominal reflexes. Even if } \\
\text { a patient has no specific indications for MRI, we } \\
\text { recommend its routine use in preoperative } \\
\text { planning. }\end{array}$ \\
\hline 7 & 2011 & Diab & 923 & $91(10 \%)$ & $\begin{array}{l}\text { Significant risk factors for neural abnormality } \\
\text { were thoracic hyperkyphosis and juvenile onset. } \\
\text { Other characteristics, including apex left } \\
\text { thoracic curve, Risser less than or equal to 1, } \\
\text { large curve magnitude, triple major curve, male } \\
\text { sex, and obesity were not associated with } \\
\text { neural abnormality. There were no differences } \\
\text { in complication rates between normal and } \\
\text { abnormal MRI patients. Our data question the } \\
\text { routine use of MRI as a screening tool } \\
\text { for adolescentidiopathic scoliosis. }\end{array}$ \\
\hline 19 & 2010 & $\mathrm{Wu}$ & 70 & $37(54 \%)$ & $\begin{array}{l}\text { When a left thoracic curve pattern is present } \\
\text { in patients with "idiopathic" scoliosis, especially } \\
\text { in male patients or patients with } \\
\text { severe curve, strong consideration should be }\end{array}$ \\
\hline
\end{tabular}




\begin{tabular}{|c|c|c|c|c|c|}
\hline & & & & & $\begin{array}{l}\text { given to the possibility of the presence } \\
\text { of neural axis abnormalities, and acquisition of } \\
\text { an MRI scan considered. }\end{array}$ \\
\hline 20 & 2010 & Richards & 529 & $36(7 \%)$ & $\begin{array}{l}\text { with those having increased rotation and/or } \\
\text { increased kyphosis at higher risk. }\end{array}$ \\
\hline 21 & 2010 & Rajasekaran & 94 & $15(16 \%)$ & $\begin{array}{l}\text { The high incidence of intraspinal anomalies in } \\
\text { presumed idiopathic scoliosis in our study group } \\
\text { emphasizes the need for detailed examination } \\
\text { for subtle neurological signs that accompany } \\
\text { neuro-axial anomalies. } \\
\text { Preoperative MRI screening is recommended } \\
\text { in patients with presumed } \\
\text { 'idiopathic' scoliosis who present at young age, } \\
\text { with neurological findings and in curves with } \\
\text { apical thoracic kyphosis. }\end{array}$ \\
\hline 22 & 2009 & Pahys & 54 & $7(13 \%)$ & $\begin{array}{c}\text { This study represents the largest evaluation } \\
\text { of intraspinal anomalies in IIS to date. Our } \\
\text { patient population exhibited a smaller } \\
\text { percentage (13\%) of neural } \\
\text { axis abnormalities than previously reported. On } \\
\text { the basis of these findings, the close } \\
\text { observation may be a reasonable alternative to } \\
\text { an immediate screening MRI in patients } \\
\text { presenting with presumed IIS and a curve }>20 \\
\text { degrees. }\end{array}$ \\
\hline
\end{tabular}

\section{Figures}




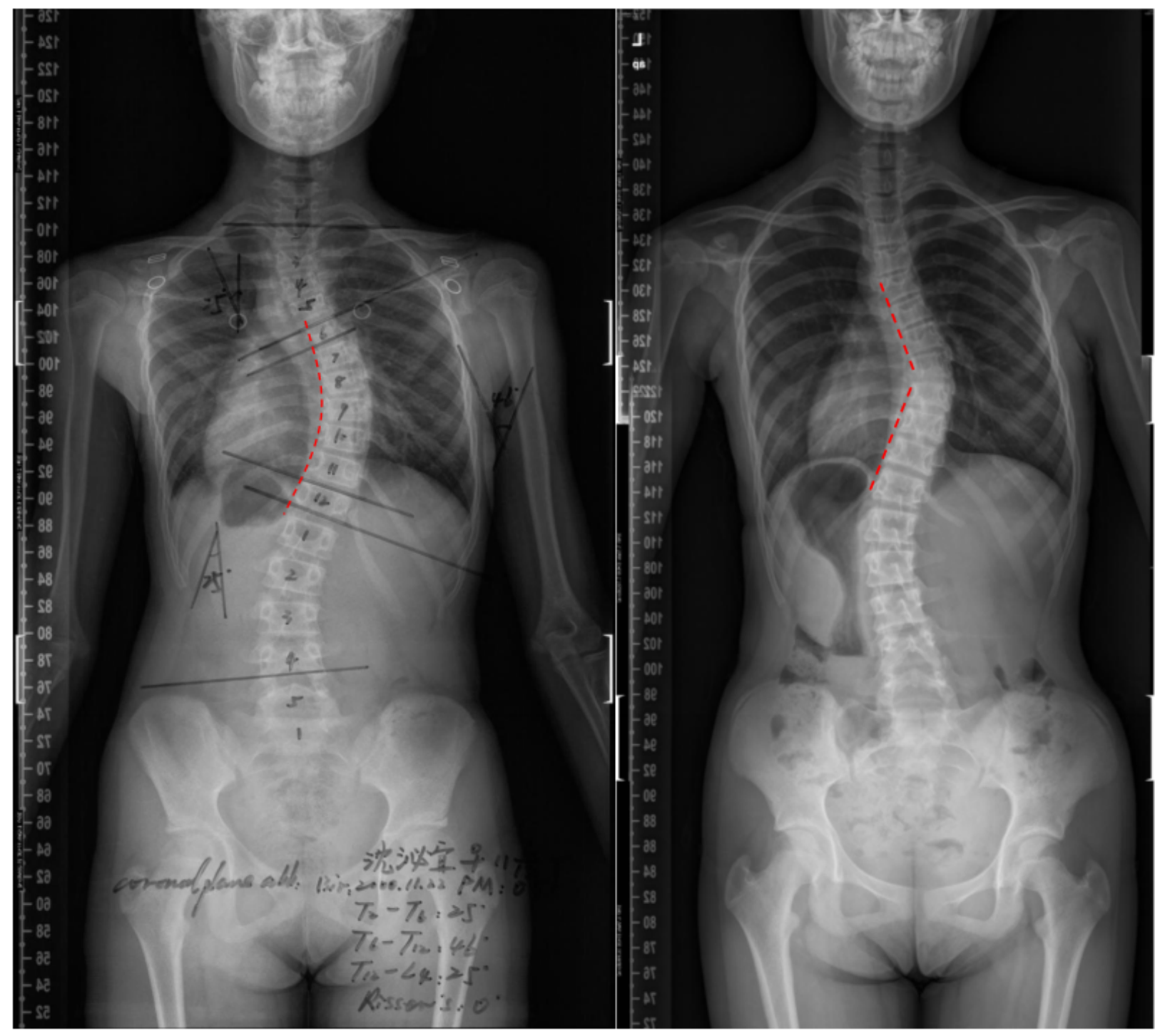

\section{Figure 1}

smooth shape is the concave side line is a smooth curve, angular shape is the concave side line is a angular curve

娄

Figure 2

The sensitivity was $66.18 \%$, the specificity was $89.01 \%$, and the Youden index corresponding to the optimal critical point was 0.5519 


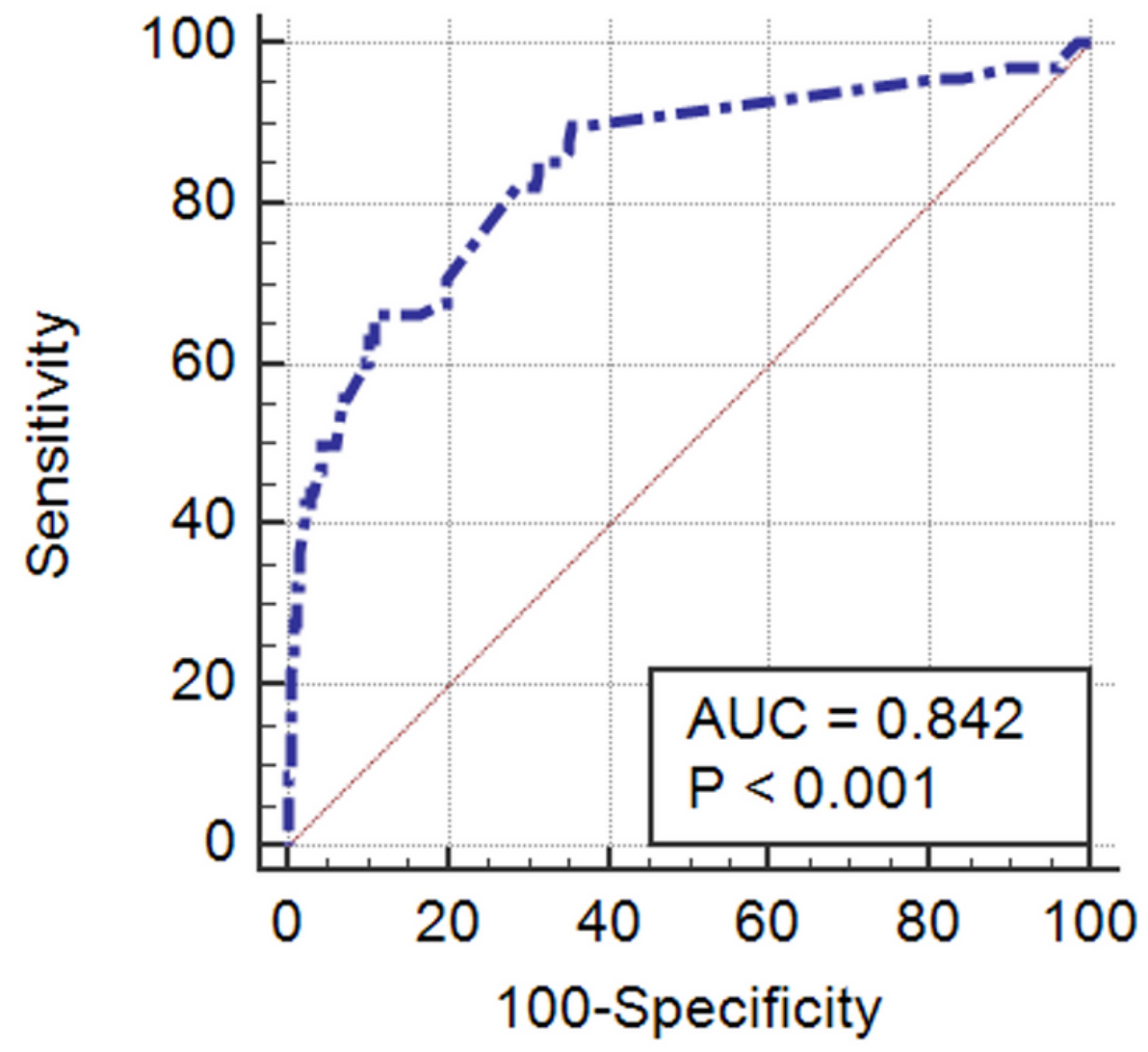

Figure 3

13-year-old female who weighed $38 \mathrm{~kg}$, was $138 \mathrm{~cm}$ tall and had a spinal deformity for 1 year. 